\title{
Thioflavones as novel neuroprotective agents
}

Article

Accepted Version

Creative Commons: Attribution-Noncommercial-No Derivative Works 4.0

Ravishankar, D., Corona, G., Hogan, S. M., Spencer, J. P. E., Greco, F. and Osborn, H. M. I. (2016) Thioflavones as novel neuroprotective agents. Bioorganic \& Medicinal Chemistry, 24 (21). pp. 5513-5520. ISSN 0968-0896 doi:

https://doi.org/10.1016/j.bmc.2016.09.006 Available at https://centaur.reading.ac.uk/66638/

It is advisable to refer to the publisher's version if you intend to cite from the work. See Guidance on citing.

To link to this article DOI: http://dx.doi.org/10.1016/j.bmc.2016.09.006

Publisher: Elsevier

All outputs in CentAUR are protected by Intellectual Property Rights law, including copyright law. Copyright and IPR is retained by the creators or other copyright holders. Terms and conditions for use of this material are defined in the End User Agreement.

\section{www.reading.ac.uk/centaur}

\section{CentAUR}

Central Archive at the University of Reading 
Reading's research outputs online 
To create your abstract, type over the instructions in the template box below.

Fonts or abstract dimensions should not be changed or altered.

\section{Thioflavones as novel neuroprotective agents}

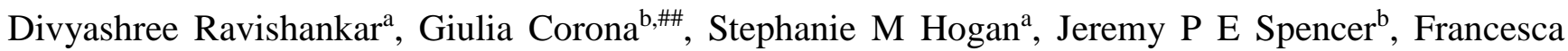
Greco $^{\text {a* }}$, Helen M I Osborn ${ }^{\text {a* }}$

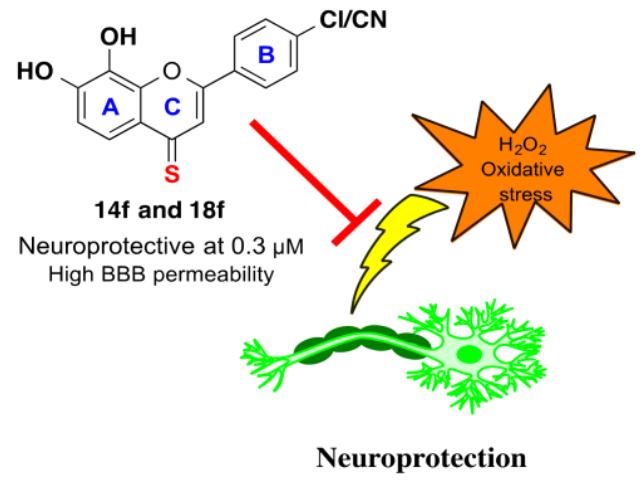




\title{
Bioorganic \& Medicinal Chemistry \\ journal homepage: www.elsevier.com
}

\section{Thioflavones as novel neuroprotective agents}

\author{
Divyashree Ravishankar ${ }^{\mathrm{a}}$, Giulia Corona ${ }^{\mathrm{b}, \#}$, Stephanie M Hogan ${ }^{\mathrm{a}}$, Jeremy P E Spencer ${ }^{\mathrm{b}}$, Francesca \\ Greco $^{\text {a* }}$, Helen M I Osborn ${ }^{\text {a* }}$ \\ ${ }^{a}$ School of Pharmacy, University of Reading, Whiteknights, RG6 6AD, Berkshire, UK. \\ ${ }^{b}$ Molecular Nutrition Group, Department of Food and Nutritional Sciences, School of Chemistry, Food and Pharmacy, University of Reading, RG6 6AP, \\ Reading, $U K$.
}

\section{ARTICLE INFO}

Article history:

Received

Revised

Accepted

Available online

\section{Keywords}

Flavones,

Oxidative stress,

Neuroprotection,

Structure-activity relationship

\section{ABSTRACT}

Oxidative stress is associated with the pathology of neurodegenerative diseases. Identification of small molecules capable of protecting against oxidative stress is therefore of significant importance. In this context, a library of 76 hydroxy flavones, methoxy flavones and their 4-thio analogues has been evaluated for neuroprotection against $\mathrm{H}_{2} \mathrm{O}_{2}$ induced oxidative stress. This revealed the synthetic 7,8-dihydroxy 4-thioflavones as neuroprotective compounds, with $\mathbf{1 4 d}$ and $\mathbf{1 8 d}$ showing highest neuroprotective effects at lower concentrations $(0.3 \mu \mathrm{M})$. Neuroprotection was found to be mediated via activation of the anti-apoptotic cell survival proteins of the ERK1/2 and PI3K/Akt pathways. Structureactivity relationship analysis revealed the B-ring phenyl group as essential for greater neuroprotection. Replacing the $4-\mathrm{C}=\mathrm{O}$ moiety with a $4-\mathrm{C}=\mathrm{S}$ moiety also generally enhanced neuroprotection. 


\section{Introduction}

Increased levels of oxidative stress are closely linked with many neurodegenerative diseases such as Parkinson's disease, Alzheimer's disease, and Amyotrophic Lateral Sclerosis $^{1-3}$. Whilst antioxidants have received attention as potential agents for managing such conditions, some clinical trials using recognised antioxidants such as vitamin E, vitamin $\mathrm{C}$, pure scavenger molecules such as boldine, and NMDA receptor blockers, have resulted in conflicting results and conclusions ${ }^{4,5}$. It is now believed that antioxidants not only reduce oxidative stress, but can also halt beneficial cellular processes. Therefore, it has been hypothesised that restoring the redox equilibrium by activation of intracellular signals involved in cell survival is more important ${ }^{6}$ than solely restoring the redox equilibrium by direct scavenging of reactive oxygen species in the course of cellular oxidative stress. Hence, therapeutic strategies that aim to identify small molecules that confer neuroprotection against oxidative stress either by activating pro-survival regulatory pathways, or by increasing endogenous cellular antioxidant defences, may offer effective treatment for these neurodegenerative diseases ${ }^{7,8}$. Identification of novel neuroprotective agents with favourable pharmacokinetic profiles and CNS distribution is also of pivotal importance for a successful clinical translation.

Flavones, a subclass of flavonoids, are polyphenolic phytochemicals that have been well recognised for their diverse pharmacological activities including neuroprotective $\mathrm{e}^{9,10}$ activities. In particular, several epidemiological in vitro and in vivo studies have highlighted the potential of flavonoids as neuroprotective agents. For example, natural flavonoids such as fisetin ${ }^{8}$, luteolin, quercetin, myricetin and hesperetin ${ }^{4,11,12}$ have been reported to protect neurons against oxidative damage. Further, several synthetic flavones ${ }^{13,14}$ and thioflavones ${ }^{15}$ have been reported to limit neurodegeneration associated with a variety of neurological disorders, namely Alzheimer's disease ${ }^{16}$ (AD) and Parkinson's disease ${ }^{17}$ (PD). Interestingly, flavonoids have been reported to increase cell survival in an oxidative stress model where scavenging antioxidants (vitamin E, boldine) failed to protect cells from the oxidative insult ${ }^{4}$. Also, growing bodies of evidence have attributed the neuroprotective abilities of flavonoids to their signalling regulation abilities ${ }^{18-21}$. Further, studies focusing on the blood-brain barrier (BBB) permeability of flavonoids have highlighted that the lipophilic flavonoids possess greater BBB permeability than the polar flavonoids ${ }^{22,23}$; the permeability potency of the compounds also correlated with their lipophilicity $(\log \mathrm{P})^{24-26}$. With our interest in developing novel flavone derivatives as therapeutic agents, we had previously synthesised and characterised a library of 76 hydroxy flavones, methoxy flavones and their 4-thio derivatives $^{27}$ (Figure-1). Intrigued by the neuroprotective potentials of flavones and by the higher lipophilicity of 4thioflavones and methoxy flavones than their corresponding hydroxy flavones, in this study, an assessment of the neuroprotective abilities of the library of 76 flavones presented herein was carried out. Also, due to the absence of a systematic investigation of the effect of substitution of the 4-carbonyl $(4-\mathrm{C}=\mathrm{O})$ group by a 4-thiocarbonyl $(4-\mathrm{C}=\mathrm{S})$ group on the neuroprotective activities of flavones, we aimed to explore the structure-activity relationships (SARs) of the library of 76 flavones presented herein

a- $\mathbf{R}_{1}, \mathbf{R}_{2},\left(\mathbf{R}_{5}, \mathbf{R}_{4}\right)$ - OMe, X=O; b- $\mathbf{R}_{1}, \mathbf{R}_{2},\left(\mathbf{R}_{9}, \mathbf{R}_{4}\right)$ - OH, X=O; C- $\mathbf{R}_{1}, \mathbf{R}_{2},\left(\mathbf{R}_{5}, \mathbf{R}_{4}\right)$ - OMe, X=S; d- $\mathbf{R}_{1}, \mathbf{R}_{2},\left(\mathbf{R}_{5}, \mathbf{R}_{4}\right)$ - OH, X=S (Total-76 compounds)

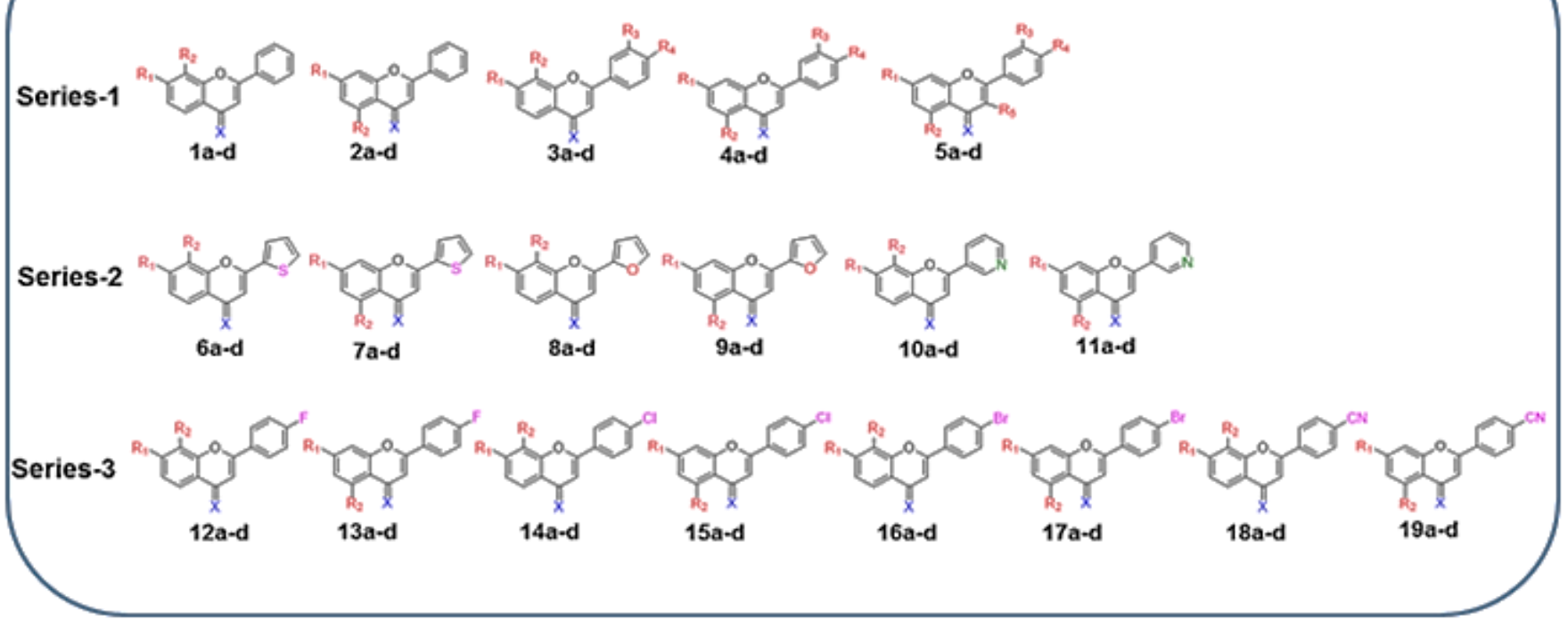

Figure 1. Structures of flavones investigated in this study. 
Please see supplementary information.

\section{Results and discussion}

\subsection{Library design}

As illustrated in Figure-1, the library of flavones is composed of three series. Each series contained methoxy flavones (designated a), hydroxy flavones (designated b), methoxy 4thioflavones (designated c) and hydroxy 4-thioflavones (designated d). The compounds in series-1 (1a-d to 5a-d) were derived from well-known flavones with different numbers and positions of hydroxyls. Series-2 was based on bioisosteric analogues of the B-ring of the active flavones from series-1 (6a-d to 11a-d). In series-3 further functionalization was incorporated via the inclusion of electron-withdrawing groups (EWGs) onto the B-ring (12a-d to 19a-d) (Figure-1). The purities of all compounds were established prior to evaluation, by reverse phase HPLC, and were found to be $>95 \%$.

\subsection{Neuroprotective evaluation}

All compounds were evaluated for their ability to protect neurons from $\mathrm{H}_{2} \mathrm{O}_{2}$-induced oxidative stress in an in vitro model using the SH-SY5Y human neuroblastoma cell line 28,29. $^{2}$. An appropriate concentration of $\mathrm{H}_{2} \mathrm{O}_{2}$ for inducing oxidative stress in SH-SY5Y cells was determined by exposing the $\mathrm{SH}$ SY5Y cells to various concentrations of $\mathrm{H}_{2} \mathrm{O}_{2}(5-500 \mu \mathrm{M})$ for $18 \mathrm{~h}$. From the cell viability assessment, using the MTT assay, it was found that $\mathrm{H}_{2} \mathrm{O}_{2}$ at $130 \mu \mathrm{M}$ ( $\mathrm{IC}_{50}$ value) induced a $50 \%$ reduction in the SH-SY5Y cell viability (Supplementary info, Figure-S1). Hence, this concentration $(130 \mu \mathrm{M})$ was used for further experiments to induce oxidative stress in SH-SY5Y cells. Next, the SH-SY5Y cells were treated with each of the compounds at the physiologically relevant concentration of 3 $\mu \mathrm{M}$ concentration ${ }^{30}$ for $24 \mathrm{~h}$ prior to exposure to $\mathrm{H}_{2} \mathrm{O}_{2}(18 \mathrm{~h})$. The cell viability was then determined by the MTT assay (Figure-2).

By comparing the neuroprotective activities of series-1, series-2 and series-3 flavones (1a-d to 19c-d) it was generally found that: -

i) Flavones bearing catecholic hydroxyl (C-7,8 hydroxyl, $o$-hydroxy) substitutions either on ring-A or -B were significantly more neuroprotective than those with $m$-hydroxyl substitutions. For example $\mathbf{2 b}$ and $\mathbf{2 d}$ with C-5,7 hydroxyl ( $m$-hydroxy) groups) were found to be inactive (cell viability < 50\%) whereas $\mathbf{1 b}, \mathbf{4 b}$ and $\mathbf{5 b}$ with catecholic hydroxyl groups confer neuroprotection by restoring the cell viability > $80 \%$. This suggests that the catecholic hydroxyl substitution is indispensable for neuroprotective activity.
The B-ring phenyl group was vital for neuroprotective activity of catecholic flavones; replacing the B-ring phenyl group with its bioisosteres [series-2 (6b, 8b, 10b, 6d, 8d and 10d); cell viability < 60\%] was detrimental for neuroprotective activity but incorporation of electron withdrawing groups on the B-ring phenyl group [series-3 (12b, 14b, 16b, 12d, 14d and 18d); cell viability $>85 \%$ ] was beneficial.

iii) Methoxy flavones were less neuroprotective than their analogous hydroxyl flavones.

iv) For the synthetic flavones in series 2 and 3, the 4-thioflavones $(\mathrm{C}=\mathrm{S})[\mathbf{1 2 f}$ (cell viability $=97.4 \pm$ $4.3 \%), \mathbf{1 4 f}$ (cell viability $=106.7 \pm 1.2 \%)$, $16 \mathbf{f}$ (cell viability $=97.8 \pm 2.6 \%$ ) and $\mathbf{1 8 f}$ (cell viability $=105.8 \pm 3.7 \%)$ ] were significantly more neuroprotective than the flavones $(\mathrm{C}=\mathrm{O})$ $[\mathbf{1 2 d}$ (cell viability $=88.8 \pm 2.5 \%), \mathbf{1 4 d}$ (cell viability $=93.4 \pm 1.4 \%), \mathbf{1 6 d}$ (cell viability $=$ $84.0 \pm 3.6 \%$ ), and 18d (cell viability = $84.6 \pm$ $1.6 \%)]$. However, the opposite trend was evident for the natural flavones in series 1 [1d (cell viability $=96.2 \pm 1.3 \%$ ) vs $\mathbf{1 f}$ (cell viability = $72.4 \pm 1.2 \%) ; \mathbf{4 d}$ (cell viability $=98.3 \pm 2.1 \%$ ) vs $4 \mathbf{f}$ (cell viability $=67.4 \pm 1.3 \%)$ ].
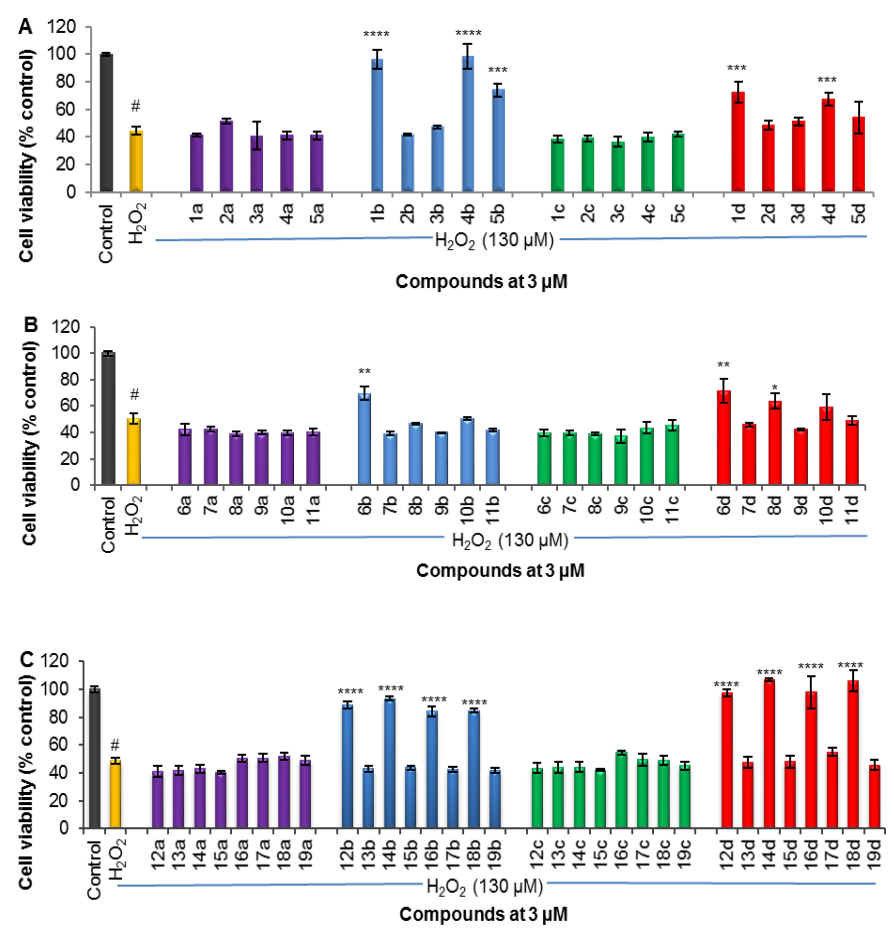

Figure 2. Neuroprotective effects of (A) Series-1 (1a-d to 5a-d) (B) Series-2 (6a-d to 11a-d) and (C) Series-3 (12a-d to 19a-d) at $3 \mu \mathrm{M}$ concentration against $\mathrm{H}_{2} \mathrm{O}_{2}$-induced oxidative stress in $\mathrm{SH}-\mathrm{SY} 5 \mathrm{Y}$ cells. Cells without treatment serve as control. Cell viability was measured by MTT assay. Statistical significance was estimated by one-way ANOVA followed by Bonferroni's post hoc test, (\#)significance with respect to the control $(\mathrm{p}<0.0001)$ and $(*)$ significance with respect to $\mathrm{H}_{2} \mathrm{O}_{2}(* \mathrm{p}<0.05$, **p $<0.01$, ***p $<$ 0.001 and $* * * * \mathrm{p}<0.0001)$. Colour coding: purple-methoxy flavone (-OMe, 4-C=O), blue-hydroxy flavone $(-\mathrm{OH}, 4-\mathrm{C}=\mathrm{O})$, green- 
methoxy 4-thioflavone (-OMe, 4-C=S) and red-hydroxy 4thioflavone (-OH, 4-C=S).

Compounds 1b, 4d, 12b, 12d, 14b, 14d, 16b, 16d, 18b and 18d that exhibited the highest neuroprotective effects at the single dose of $3 \mu \mathrm{M}$ were further evaluated at lower concentrations to determine their ability to exert neuronal protection against $\mathrm{H}_{2} \mathrm{O}_{2}$-induced oxidative stress. Whilst no significant protective effects were observed at lower concentrations for $\mathbf{1 b}, \mathbf{4 b}, \mathbf{1 2 b}, \mathbf{1 2 d}, \mathbf{1 4 b}, \mathbf{1 6 b}$, compounds 14d and 18d were found to be effective even at $0.3 \mu \mathrm{M}$ concentration (cell viability $>70 \%$ ) (Figure-3). Importantly, compounds $1 \mathrm{~b}, \mathbf{4 d}, \mathbf{1 2 b}, 12 \mathrm{~d}, 14 \mathrm{~d}, 16 \mathrm{~b}$ and $18 \mathrm{~d}$ were found to be nontoxic to SH-SY5Y cells at $3 \mu \mathrm{M}$ and $10 \mu \mathrm{M}$ doses for $24 \mathrm{~h}$ (as evidenced using the MTT assay). However, compound 16d caused 52\% reduction in the cell viability at $10 \mu \mathrm{M}, \mathrm{p}<0.001$ (Figure-4).
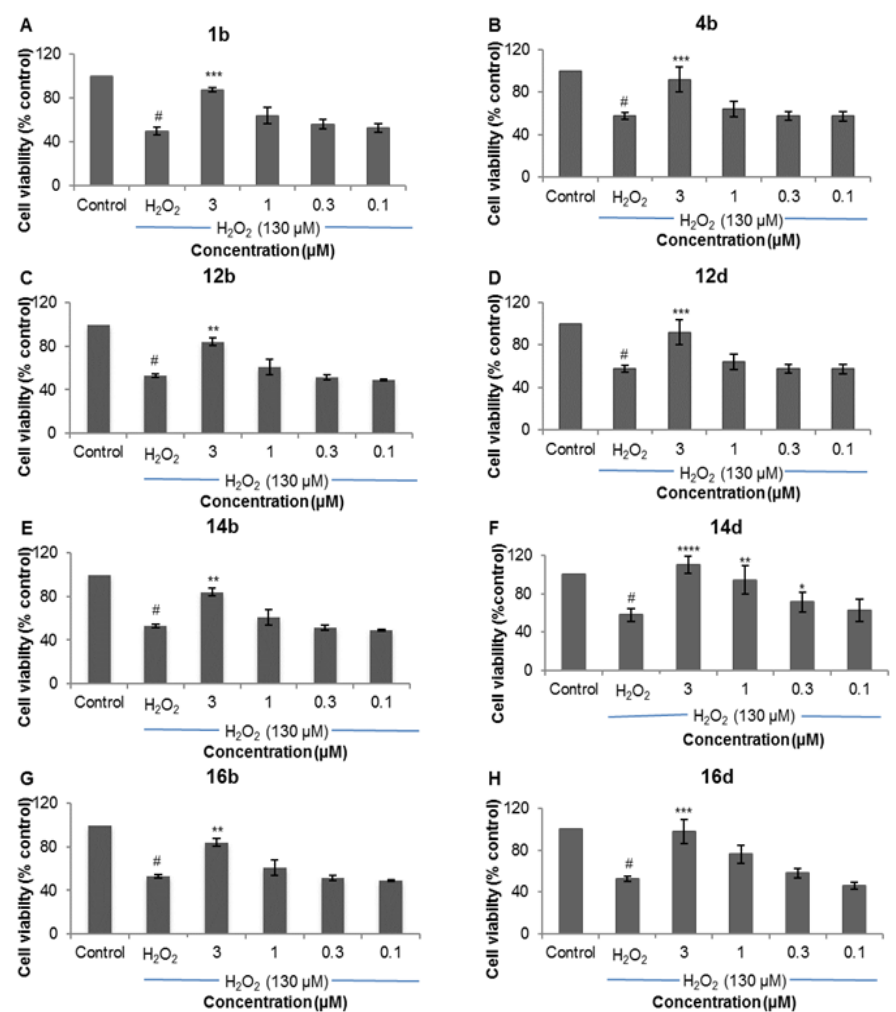

Figure 3. Neuroprotective effects of (A) Compound-1b, (B) Compound-4b, (C) Compound-12b, (D) Compound-12d, (E) Compound-14b, (F) Compound-14d, (G) Compound-16b, (H) Compound-16d, (I) Compound-18b, and (J) Compound-18d in a dose dependent manner in the concentration range 0.1-3 $\mu \mathrm{M}$ against $\mathrm{H}_{2} \mathrm{O}_{2}$-induced oxidative stress in SH-SY5Y cells. Cells without treatment serve as control. Data are expressed as the mean \pm standard error of the mean $(\mathrm{SEM})(\mathrm{n}=3)$. Statistical significance was estimated by one-way ANOVA followed by Bonferroni's post hoc test, (\#)-significance with respect to the control ( $\mathrm{p}<0.0001)$ and $(*)-$ significance with respect to $\mathrm{H}_{2} \mathrm{O}_{2}(* * \mathrm{p}<0.01$ and $* * * \mathrm{p}<0.001)$.

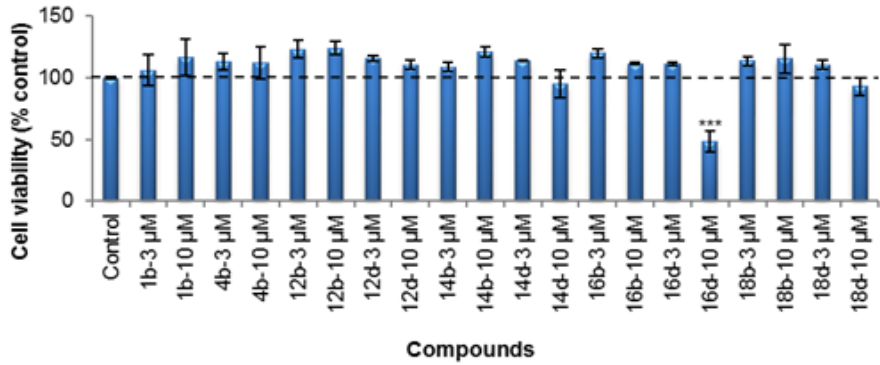

Figure 4. Toxic effects of compounds 1b, 4d, 12b, 12d, 14b, 14d, 16b, 16d, 18b and 18d evaluated at 3 and $10 \mu \mathrm{M}$ concentrations against SH-SY5Y cells. Cells without treatment serve as control. Data are expressed as the mean \pm standard error of the mean (SEM) $(n=3)$. Statistical significance was estimated with respect to the control by one-way ANOVA, followed by Bonferroni's post hoc test $(* * * \mathrm{p}<0.001)$

\subsection{Molecular mechanism of neuroprotection}

Flavones can act either as a free radical scavenger (antioxidant) or can trigger intracellular pathways for cell survival. Therefore, to gain insight into the mechanism of neuroprotection, their antioxidant potentials and impact on certain intracellular signalling targets were explored.

\subsubsection{Antioxidant activity}

Flavones are very well known for their antioxidant activities $^{31,32}$, therefore the antioxidant properties of flavones 1b (7,8-dihydroxy flavone), 4b (luteolin, a well-known natural flavone) and compound-14b with a $4-\mathrm{C}=\mathrm{O}$ moiety, as well as the most neuroprotective 4-thioflavones (with 4-C=S) 14d, 16d and 18d were studied. For this, the flavones were evaluated at their neuroprotective concentration of $3 \mu \mathrm{M}$ both for their ability to directly interact with free radicals (primary antioxidant activity) using a DPPH free radical scavenging assay and for their ability to bind to ferrous $\left(\mathrm{Fe}^{2+}\right)$ ion that catalyses oxidation (secondary antioxidant activity), using a metal chelating assay (Table-1). As shown in Table 1, all the aforementioned flavones showed very low scavenging activity (only up to $1.9 \%$ inhibition of DPPH radical) at $3 \mu \mathrm{M}$. Also, based on previous reports on DPPH scavenging data for the well-known flavones (1b and $\mathbf{4 d}$, Series-1), no correlation was found between the order of their neuroprotective abilities [1b $($ Cell viability-97\%) > 4d (Cell viability-73\%, p < 0.05)] and the order of their scavenging activity [DPPH radical scavenging activity- $\mathrm{IC}_{50}-\mathbf{4 d}(11.04 \pm 0.38 \mu \mathrm{M})>\mathbf{1 b}(15.50 \pm$ $0.12 \mu \mathrm{M})]^{33}$. Since, in general, compounds with catechol groups are defined as effective metal chelators ${ }^{34-36}$, the ironchelating ability of flavones $1 \mathbf{b}, \mathbf{4 d}, \mathbf{1 4 b}, 14 d, 16 d$ and $18 d$ at $3 \mu \mathrm{M}$ was further studied. Interestingly, a low degree of $\mathrm{Fe}^{2+}$ chelation (only up to $5 \%$ ) was exhibited by these flavones at 3 $\mu \mathrm{M}$ concentration (Table 1 ).

Taken together, there was no observed correlation between the neuroprotective profiles and the antioxidant activities of flavones at their tested concentration. Therefore, it is possible that the flavones directly interact with cellular events leading to cell death after oxidative stress. Hence, the intracellular 
signalling pathways triggered by flavones in oxidative-stress induced SH-SY5Y cells were probed.

Table 1. Antioxidant activities of flavones

\begin{tabular}{ccc}
\hline \multirow{2}{*}{ Flavone } & \multicolumn{2}{c}{ Antioxidant activity at $\mathbf{3} \boldsymbol{\mu M}$ concentration } \\
\cline { 2 - 3 } & $\begin{array}{c}\text { DPPH scavenging assay } \\
\text { (Scavenging activity, \%) }\end{array}$ & $\begin{array}{c}\text { Metal chelating assay } \\
\left(\mathrm{Fe}^{2+} \text { chelating activity, } \%\right)\end{array}$ \\
\hline $1 \mathrm{~b}$ & $1.4 \pm 0.2$ & $3.7 \pm 1.0$ \\
\hline $4 \mathrm{~b}$ & $1.9 \pm 0.2$ & $3.4 \pm 0.4$ \\
\hline $14 \mathrm{~b}$ & $1.4 \pm 0.5$ & $3.7 \pm 1.2$ \\
\hline $14 \mathrm{~d}$ & $1.7 \pm 0.2$ & $5.0 \pm 1.6$ \\
\hline $16 \mathrm{~d}$ & $1.6 \pm 0.6$ & $4.4 \pm 1.7$ \\
\hline $18 \mathrm{~d}$ & $1.3 \pm 0.2$ & $3.9 \pm 0.4$ \\
\hline $\begin{array}{c}\text { Ascorbic } \\
\text { acid }\end{array}$ & $1.3 \pm 0.5$ & - \\
\hline EDTA $^{\mathrm{c}}$ & - & $6.9 \pm 0.4$ \\
\hline
\end{tabular}

${ }^{a}$ Data expressed as Mean \pm SEM, $\mathrm{n}=3$; ${ }^{\mathrm{b}}$ Ascorbic acid was used as a reference standard for the DPPH scavenging assay, $\mathrm{IC}_{50}$ value of ascorbic acid for the inhibition of DPPH radical formation was established to be $330 \pm 0.5 \mu \mathrm{M}$ (Supplementary info, Figure-S2); 'EDTA was used as a reference standard for the metal chelating assay, $\mathrm{IC}_{50}$ value of EDTA in metal chelating assay was determined to be $42 \pm 0.8 \mu \mathrm{M}$ (Supplementary info, Figure-S3).

\subsubsection{Intracellular signalling}

Accumulative evidence has shown that flavonoids display signalling properties during neuroprotection ${ }^{12,21,37-40}$. Hence, the potential intracellular signalling involved in the neuroprotective function of flavones were probed. For this, the signal mediated in SH-SY5Y cells by the well-known compounds 1b, 4b (luteolin) and compound-14b with a 4$\mathrm{C}=\mathrm{O}$ moiety, as well as the neuroprotective 4-thioflavones (with 4-C=S) 14d, 16d and 18d were studied. Pooled samples from three independent treatments of SH-SY5Y cells with and without $\mathrm{H}_{2} \mathrm{O}_{2}(130 \mu \mathrm{M})$, and with these compounds at $3 \mu \mathrm{M}$ concentration for $24 \mathrm{~h}$ followed by the exposure to $\mathrm{H}_{2} \mathrm{O}_{2}$ (1 h) $)^{38}$, were analysed using the PathScan $^{\circledR}$ Intracellular Signalling Array Kit (Figure-5). These compounds were found to modulate the signalling molecules that are associated with cellular survival and apoptosis such as ERK1/2, mTOR, AMPK $\alpha$ and Akt targets such as Bad and PRAS40. Treatment of SH-SY5Y cells with $\mathrm{H}_{2} \mathrm{O}_{2}(130 \mu \mathrm{M})$ resulted in a marked reduction in phosphorylation of ERK1/2, mTOR, Bad and PRAS40. Pre-treatment with 7,8-dihydroxy flavones (containing $4-\mathrm{C}=\mathrm{O}$ ) showed that compounds $\mathbf{1 b}$ and $\mathbf{4 b}$ were able to confer neuroprotection by the inhibition of apoptosis through restoration of $\mathrm{Bad}$ (a pro-apoptotic protein) phosphorylation (by inactivating its apoptotic activity), whereas, compound 14b was shown to elicit its activity through restoration of mTOR phosphorylation, which restores protein synthesis. In the case of 4-thioflavones, compound 14d significantly restored phosphorylation of ERK1/2, mTOR, Bad and PRAS40 up to the same levels or higher than that observed in the control, along with activation of AMPK $\alpha$. Also, compound $\mathbf{1 8 d}$ was found to restore phosphorylation of
ERK1/2 and mTOR, along with activation of AMPK $\alpha$, however, compound 16d showed restoration of $\mathrm{Bad}$ phosphorylation only. These results support the in vitro observations and suggest that the neuroprotective effects of flavones are mediated via ERK1/2 and PI3K/Akt/mTOR pathways and that these flavones differentially activate the pro-survival protein kinases based on their chemical structure. Also, a comparison of intracellular signalling of the 4thioflavone 14d with its corresponding flavone 14b highlights the beneficial influence of $4-C=S$ substitution on the neuroprotective activity. Thus, the enhanced neuroprotective effects of compounds $\mathbf{1 4 d}$ and $\mathbf{1 8 d}$ can be attributed to their potential to modulate multiple signalling targets. As several studies have highlighted compound-1b as a promising small molecular BDNF mimetic, with selective TrkB (Tropomyosin-related kinase B) receptor agonist activity ${ }^{41-47}$, it may be pertinent to explore the roles of compounds $\mathbf{1 4 d}$ and 18d in the modulation of the TrkB receptor in the future.
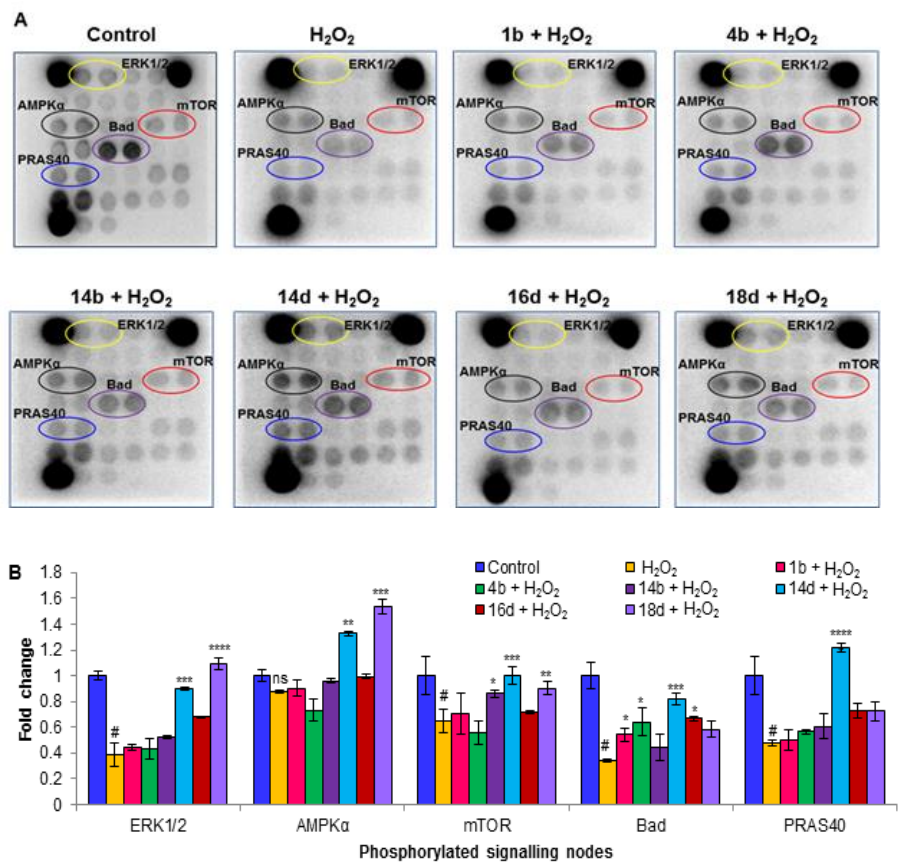


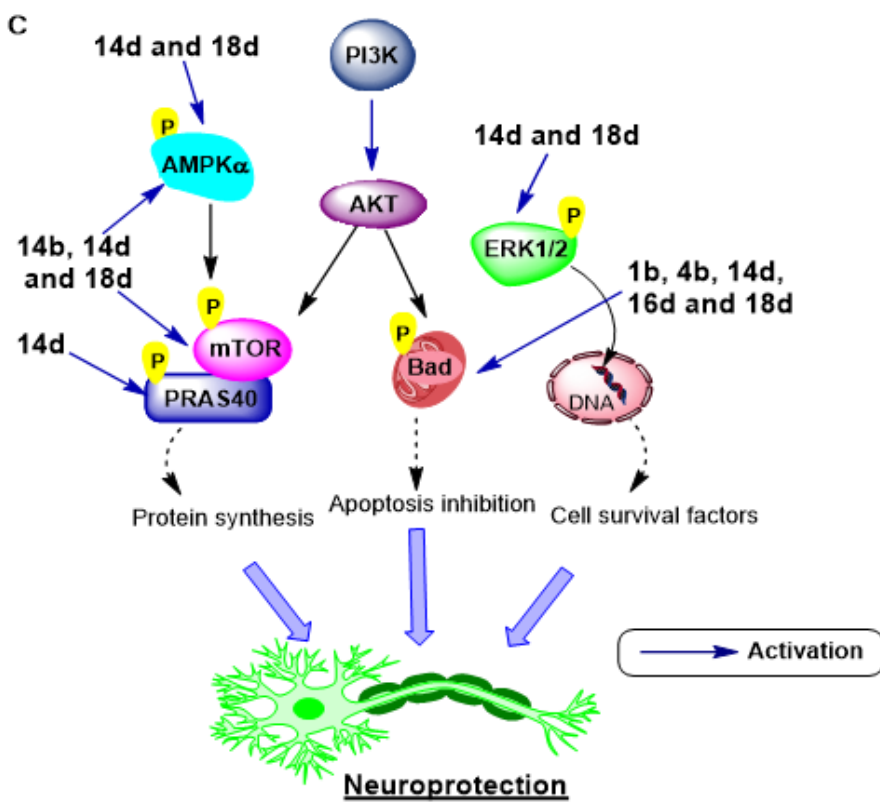

Figure 5. (A) Chemiluminescent array images of the PathScan Intracellular Signalling array kit revealing various phosphorylated in SH-SY5Ycells pre-treated with and without compounds $\mathbf{1 b}, \mathbf{4 b}, \mathbf{1 4 b}$, 14d, 16d and 18d at $3 \mu \mathrm{M}$ for $24 \mathrm{~h}$ before exposure to $\mathrm{H}_{2} \mathrm{O}_{2}(130$ $\mu \mathrm{M})$. Cells without treatment serve as control. (B) Bar chart representing the fold change in the integrated density of phosphorylated signalling nodes in the array image of SH-SY5Ycells pre-treated with and without compounds 1b, 4b, 14b, 14d, 16d and 18d at $3 \mu \mathrm{M}$ for $24 \mathrm{~h}$ before exposure to $\mathrm{H}_{2} \mathrm{O}_{2}(130 \mu \mathrm{M})$. Data are expressed as the mean \pm standard error of the mean (SEM) $(n=4)$. Statistical significance was estimated with respect to the control (\#) and with respect to $\mathrm{H}_{2} \mathrm{O}_{2}$ (*) by one-way ANOVA, followed by Bonferroni's post hoc test (ns-not significant, *p $<0.05$, **p $<0.01$, $* * * \mathrm{p}<0.001$ and $* * * * \mathrm{p}<0.001)$. (C) Molecular mechanism of action of $\mathbf{1 b}, \mathbf{4 b}, \mathbf{1 4 b}, \mathbf{1 4 d}, \mathbf{1 6 d}$ and $\mathbf{1 8 d}$ in SH-SY5Y cell line.

\subsubsection{In silico prediction of $B B B$ permeability}

For the flavones to be able to exert their neuroprotective effect clinically, permeation across the BBB is required. Therefore, BBB permeability scores were calculated for each flavone. These BBB permeability scores were then plotted against the neuroprotective ability to identify the most promising candidates (i.e. compounds with both high predicted permeation across the BBB and high neuroprotective activity, Figure-6). This showed that synthetic thioflavone compounds 14d and 18d possess both high neuroprotective ability (cell viability $>95 \%$, neuroprotective even at $0.3 \mu \mathrm{M}$ concentration) and high BBB permeability (BBB score > 0.02). In contrast, the natural/well-known flavones such as 7,8-dihydroxy flavone (1) $)$, luteolin $(\mathbf{4 b})$ and quercetin $(\mathbf{5 b})$ were found to be neuroprotective but their poor BBB permeability scores might undermine the likelihood of achieving sufficiently high concentrations in the central nervous system. Therefore, the synthetic thioflavones $14 d$ and 18d can be considered as lead candidates for further design and development of neuroprotective agents.

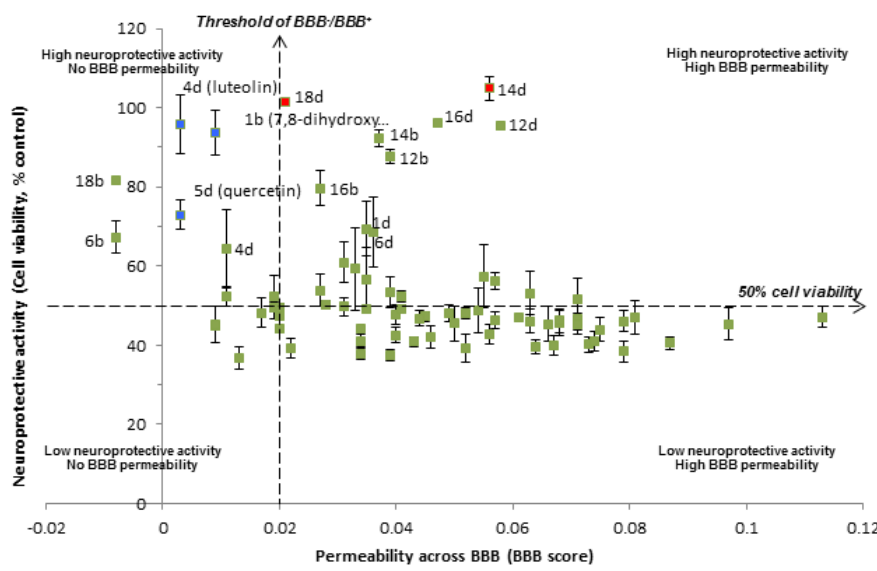

Figure 6. Graph represents BBB permeability of compounds (predicted BBB score) versus neuroprotective activity (cell viability) determined at $3 \mu \mathrm{M}$ using the SH-SY5Y neuroblastoma cell line. The dashed line at $\mathrm{x}=0.02$ represents the threshold BBB-/BBB+ score and the dashed line at $\mathrm{y}=50$ represents $50 \%$ cell viability in SH-SY5Y cells exposed to $\mathrm{H}_{2} \mathrm{O}_{2}$. Neuroprotective natural flavone/well-known flavones are highlighted in blue and the thioflavones that have been identified to be neuroprotective are highlighted in red. Lower left quadrant represents low neuroprotective activity and no BBB permeability, lower right quadrant represents low neuroprotective activity and high BBB permeability, upper left quadrant represents high neuroprotective activity and no BBB permeability and upper right quadrant represents high neuroprotective activity and high BBB permeability.

\section{Conclusion}

In summary, evaluation of the neuroprotective properties of structurally related methoxy flavones, hydroxy flavones and their 4-thio analogues has provided significant insights into the SARs of flavones, as summarised in Figure 7.

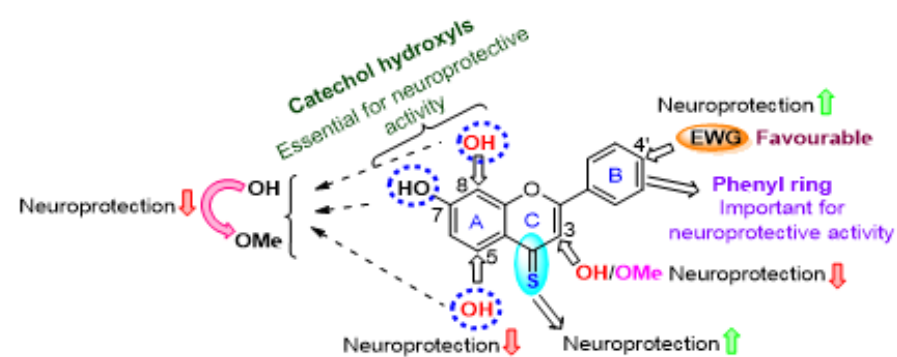

Figure 7. Summary of the SARs on the neuroprotective activities of flavones.

Overall, 7,8-dihydroxy 4-thioflavones such as compounds 14d and 18d were found to exhibit potent neuroprotective effects against $\mathrm{H}_{2} \mathrm{O}_{2}$-induced oxidative stress with their activity being restored even at $0.3 \mu \mathrm{M}$ concentration. For 14d and 18d, high BBB permeability is also predicted. Investigations of the molecular mechanism of action of $\mathbf{1 4 d}$ and 18d indicated that these compounds preferably mediate their neuroprotective effects through suppression of apoptosis by activating the anti-apoptotic proteins, and inactivating the pro-apoptotic proteins of the ERK1/2 and PI3K/Akt/mTOR pathways that are deregulated in $\mathrm{AD}^{48}$ and $\mathrm{PD}^{49}$. As such, 
small molecules have been identified that confer neuroprotection against oxidative stress by activating prosurvival regulatory pathways. Therefore, the synthetic flavones 14d and $\mathbf{1 8 d}$ can be considered as promising candidates for further optimisation and development as neuroprotective agents. In this regard, future studies that will decipher the pharmacokinetic and pharmacodynamic properties of these synthetic compounds will further guide the optimisation of these candidates for neuroprotective applications.

\section{Corresponding Authors}

*Helen. M. I. Osborn.

Tel: +44 (0)118 378-7338,

E-mail address: h.m.i.osborn@reading.ac.uk.

\section{*Francesca Greco}

Tel: +44 (0) 118 378-8244

E-mail address: f.greco@reading.ac.uk

\section{Present Addresses}

Reading School of Pharmacy, University of Reading, Whiteknights, Reading, UK, RG6 6AD.

\section{Acknowledgments}

Financial support to DR from the Felix trust is gratefully acknowledged. We thank Amit Kumar Rajora for his help with the sample preparation for microarray experiment. We also thank the University of Reading for the provision of the Chemical Analysis Facility.

\section{Abbreviations}

MTT-3-(4,5-dimethylthiazol-2-yl)-2,5-diphenyltetrazolium bromide, DPPH-2,2-diphenyl-1-picrylhydrazyl, EDTAEthylenediaminetetraacetic acid, ERK1/2-extracellular signalregulated kinase, mTOR-mammalian target of rapamycin, AMPK $\alpha-5$ ' adenosine monophosphate-activated protein kinase, GSK-3 $\beta$ - Glycogen synthase kinase-3 $\beta$, Bad-Bcl-2associated death promoter, PRAS40-proline-rich Akt substrate of $40 \mathrm{kDa}$, PI3K-Phosphatidylinositol-4,5bisphosphate-3-kinase, BDNF-brain-derived neurotrophic factor.

\section{References}

1. Uttara, B.; Singh, A. V; Zamboni, P.; Mahajan, R. T. Curr Neuropharmacol. 2009, 7, 65-74.

2. Rossignol, D. A.; Frye, R. E. Front. Physiol. 2014, 5.

3. Andersen, J. K. Nat. Med. 2004, 10 Suppl, S18-S25.

4. Dajas, F.; Rivera-Megret, A.; Blasina, F.; Arrendondo, F.; AbinCarriquiry, J. A.; Costa, G.; Echeverry, C.; Lafon, L.; Heizen, H.; Ferreira, M.; Morquio, A. Brazilian J. Med. Biol. Res. 2003, 36 , 1613-1620.

5. Mecocci, P.; Polidori, M. C. Biochim. Biophys. Acta 2012, 1822 631-8

6. Freeman, L. R.; Keller, J. N. Biochim. Biophys. Acta-Mol. Basis Dis. 2012, 1822, 822-829.
A. Lapchak, P. Curr. Pharm. Des. 2012, 18, 3694-3703. Chiruta, C.; Schubert, D.; Dargusch, R.; Maher, P. J. Med. Chem. 2012, 55, 378-389.

Nakayama, M.; Aihara, M.; Chen, Y.-N.; Araie, M.; TomitaYokotani, K.; Iwashina, T. Mol. Vis. 2011, 17, 1784-1793. Gutierrez-Merino C, Lopez-Sanchez C, Lagoa R, Samhan-Arias AK, Bueno C, G.-M. V. Curr Med Chem. 2011, 18, 1195-212. Vauzour, D.; Vafeiadou, K.; Rodriguez-Mateos, A.; Rendeiro, C.; Spencer, J. P. E. Genes Nutr. 2008, 3, 115-126.

Rainey-Smith, S.; Schroetke, L.-W.; Bahia, P.; Fahmi, A.; Skilton, R.; Spencer, J. P. E.; Rice-Evans, C.; Rattray, M.; Williams, R. J. Neurosci. Lett. 2008, 438, 29-33.

Li, X. H.; Dai, C. F.; Chen, L.; Zhou, W. T.; Han, H. L.; Dong, Z. F. CNS Neurosci. Ther. 2016, 22, 617-24.

Gao, L.; Tian, M.; Zhao, H. Y.; Xu, Q. Q.; Huang, Y. M.; Si, Q. C.; Tian, Q.; Wu, Q. M.; Hu, X. M.; Sun, L. B.; McClintock, S. M.; Zeng, Y. J. Neurochem. 2016, 136, 620-636.

Gaspar, A.; Silva, T.; Yáñez, M.; Vina, D.; Orallo, F.; Ortuso, F.; Uriarte, E.; Alcaro, S.; Borges, F. J. Med. Chem. 2011, 54, 51655173

Baptista, F. I.; Henriques, A. G.; Silva, A. M. S.; Wiltfang, J.; Da Cruz E Silva, O. A. B. ACS Chem. Neurosci. 2014, 5, 83-92.

Spencer, J. P. E. Chem. Soc. Rev. 2009, 38, 1152-1161. Stevenson, D. E.; Hurst, R. D. Cell. Mol. Life Sci. 2007, 64, 29002916

Vauzour, D.; Vafeiadou, K.; Rice-Evans, C.; Williams, R. J.; Spencer, J. P. E. J. Neurochem. 2007, 103, 1355-1367. Williams, R. J.; Spencer, J. P. E.; Rice-Evans, C. Free Radic. Biol. Med. 2004, 36, 838-849.

Spencer, J. P. E. Genes Nutr. 2007, 2, 257-273.

Youdim, K. A.; Dobbie, M. S.; Kuhnle, G.; Proteggente, A. R.; Abbott, N. J.; Rice-Evans, C. J. Neurochem. 2003, 85, 180-192. Yang, Y.; Bai, L.; Li, X.; Xiong, J.; Xu, P.; Guo, C.; Xue, M. Toxicol. Vitr. 2014, 28, 388-396.

Wager, T. T.; Hou, X.; Verhoest, P. R.; Villalobos, A. ACS Chem. Neurosci. 2010, 1, 435-449.

Lipinski, C. A. J. Pharmacol. Toxicol. Methods 2000, 44, 235-249. Ricci, M.; Blasi, P.; Giovagnoli, S.; Rossi, C. Curr. Med. Chem. 2006, 13, 1757-1775.

Ravishankar, D.; Watson, K.; Greco, F.; Osborn, H.M.I. RSC Adv. 2016, 6, 64544-64556.

Whittemore, E. R.; Loo, D. T.; Watt, J. A.; Cotmans, C. W. Neuroscience 1995, 67, 921-932.

Zhang, L.; Zhao, B. Y.; Yew, D. T.; Kusiak, J. W.; Roth, G. S. Biochem. Biophys. Res. Commun. 1997, 235, 845-848.

Kroon, P. A.; Clifford, M. N.; Crozier, A.; Day, A. J.; Donovan, J. L.; Manach, C.; Williamson, G. Am. J. Clin. Nutr. 2004, 80, 15-21. Pietta, P. G. J. Nat. Prod. 2000, 63, 1035-1042.

Procházková, D.; Boušová, I.; Wilhelmová, N. Fitoterapia 2011, 82, 513-523.

Seyoum, A.; Asres, K.; El-Fiky, F. K. Phytochemistry 2006, 67, 2058-2070.

Andjelković, M.; Van Camp, J.; De Meulenaer, B.; Depaemelaere, G.; Socaciu, C.; Verloo, M.; Verhe, R. Food Chem. 2006, 98, 2331.

Kawabata, T.; Schepkin, V.; Haramaki, N.; Phadke, R. S.; Packer, L. Biochem. Pharmacol. 1996, 51, 1569-1577.

Chavarria, D.; Silva, T.; Martins, D.; Bravo, J.; Summavielle, T.; Garrido, J.; Borges, F. Med. Chem. Commun. 2015, 6, 1043-1053. Hwang, S.-L.; Shih, P.-H.; Yen, G.-C. J. Agric. Food Chem. 2012 , 60, 877-85

Angeloni, C.; Spencer, J. P. E.; Leoncini, E.; Biagi, P. L.; Hrelia, S Biochimie 2007, 89, 73-82.

Spencer, J. P. E.; Rice-Evans, C.; Williams, R. J. J. Biol. Chem. 2003, 278, 34783-34793.

Incani, A.; Deiana, M.; Corona, G.; Vafeiadou, K.; Vauzour, D.; Dessì, M. A.; Spencer, J. P. E. Mol. Nutr. Food Res. 2010, 54, 788796.

Jang, S.-W.; Liu, X.; Yepes, M.; Shepherd, K. R.; Miller, G. W.; Liu, Y.; Wilson, W. D.; Xiao, G.; Blanchi, B.; Sun, Y. E.; Ye, K. Proc. Natl. Acad. Sci. U. S. A. 2010, 107, 2687-2692.

Castello, N. A.; Nguyen, M. H.; Tran, J. D.; Cheng, D.; Green, K. N.; LaFerla, F. M. PLoS One 2014, 9.

Wu, C. H.; Hung, T. H.; Chen, C. C.; Ke, C. H.; Lee, C. Y.; Wang, P. Y.; Chen, S. F. PLoS One 2014, 9.

Andero, R.; Daviu, N.; Escorihuela, R. M.; Nadal, R.; Armario, A. Hippocampus 2012, 22, 399-408. Liu, X.; Chan, C. B.; Jang, S. W.; Pradoldej, S.; Huang, J.; He, K.; 
Phun, L. H.; France, S.; Xiao, G.; Jia, Y.; Luo, H. R.; Ye, K. J Med. Chem. 2010, 53, 8274-8286.

47. Mantilla, C. B.; Ermilov, L. G. Muscle and Nerve 2012, 45, 274276.

48. Liu, Y.; Liu, F.; Grundke-Iqbal, I.; Iqbal, K.; Gong, C.-X. J. Pathol. 2011, 225, 54-62.

49. Jha, S. K.; Jha, N. K.; Kar, R.; Ambasta, R. K.; Kumar, P. Int. J. Mol. Cell. Med. 2015, 4, 67-86.

\section{Notes}

The authors declare no competing financial interest. ${ }^{\#}$ Author Giulia Corona is currently available at Health Sciences
Research Centre, Life Sciences Department, University of Roehampton, SW15 4JD, London, UK.

\section{Supplementary Material}

Supporting Information Available: This includes materials and methods, the dose-dependent curves of $\mathrm{H}_{2} \mathrm{O}_{2}$, ascorbic acid and EDTA. Theoretical BBB scores calculated using the online prediction tools are also given. 
